\title{
GROWTH AND SPECTROSCOPIC CHARACTERIZATION OF UREA SULPHAMIC ACID CRYSTAL: A SECOND-ORDER NONLINEAR MATERIAL
}

\author{
N. Senthilvelan", ${ }^{1, *}$ G. Rajarajan², A.Jegatheesan ${ }^{3}$, S. Sivakumar ${ }^{4}$ \\ and J. Elanchezhiyan ${ }^{1}$ \\ ${ }^{1}$ Department of Physics, Arignar Anna Government Arts College, Attur-636121,India \\ ${ }^{2}$ Department of Physics, Vidhya Mandhir Institute of Technology, Erode-638052, India \\ ${ }^{3}$ Department of Physics, Pavai College of Technology, Namakkal - 637018, India \\ ${ }^{4}$ Department of Physics, Government Arts College, Salem-636007, India \\ *E-mail: nsenthilvelan2013@gmail.com
}

\begin{abstract}
An organic single crystal of Urea Sulphamic Acid crystals (US) was grown by slow evaporation technique at room temperature $\left(30^{\circ} \mathrm{C}\right)$. The structure of grown crystal was discovered from the X-ray diffraction study and it belongs to the triclinic system. Vibrational modes of Urea Sulphamic crystal was identified by the employing FTIR spectral analysis. UV-Visible spectral studies showed that the lower cut-off wavelength was found to be $236 \mathrm{~nm}$. The impedance study has been carried out and it was showing a maximum at low frequency and decreases with increasing frequency. The thermal stability of the crystal was determined by employing thermo-gravimetric analysis (TGA) and differential scanning calorimetry (DSC) methods for the grown crystal. Second harmonic generation measurement indicate that the efficiency of urea sulphamic acid nonlinear crystal was 1.1 times greater than that of KDP crystal.The analysis results confirmed that these crystals have better nonlinearity and good mechanical strength.
\end{abstract}

Keywords:US NLO Crystal, Organic Crystal, XRD, FTIR, UV, TGA, SHG

@) RASĀYAN. All rights reserved

\section{INTRODUCTION}

The emergence of nonlinear optical (NLO) crystals as one of the most attractive fields of research in recent years due to its vital applications in the areas like optical data storage in telecommunications, optical switching, optical modulation, frequency shifting, optical logic and signal processing. ${ }^{1-3}$ Organic single crystal growth has greatly increased due to their applications in optoelectronics and nonlinear optics. Organic materials lead to growth-related problems because of their intrinsic properties such as low thermal conductivity, ease of super cooling and low melting point and weaker mechanical properties. ${ }^{4}$ The organic crystals have properties whose symmetry is described by odd-rank tensors such as pyro-electric effect, spontaneous electric polarization, piezoelectric effect, generation of second optical harmonics, etc. ${ }^{5}$ The attention of researchers turned towards organo-inorganic hybrid materials in recent years, in particular, the inorganic derivatives are often attributed to symmetric groups without an inversion center mostly to polar symmetry groups. ${ }^{6,7} \mathrm{~A}$ strong inorganic sulphamic acid $(\mathrm{SA})\left(\mathrm{H}_{2} \mathrm{NSO}_{3} \mathrm{H}\right)$ is the monoamide of sulphamic acid while mixing it with water it exhibits Zwitterionic form and has large applications as anti-corrosive agent. ${ }^{89}$ Urea $\left(\mathrm{CH}_{4} \mathrm{~N}_{2} \mathrm{O}\right)$, an organic compound exhibits wide nonlinear optical coefficients, high laser damage threshold and a high degree of bifringence ${ }^{10-13}$.Urea is a biological natural compound typically found in the urine of mammals. There are several different usages and applications of it, such as in feedstock, glue, fertilizer, commercial products, and resin production. It is extensively used in many developing countries of the world and predominant worldwide markets due to it' sinexpensivemanufacturing and transportation charges. It is occasionally known as carbamide also. The utmost common application of urea is fertilizer across the world because it is produced over $90 \%$ for 
fertilizer-related products only. The urea usually takes the form of granules, pills or crystals when produced as fertilizer. The fertilizer urea normally distributed by farmers manually or scattered with the aid of farming equipment and also often used in fertilizing as urea solutions, since it is extremely water soluble. Sulphamic Acid $\left(\mathrm{H}_{2} \mathrm{NSO}_{3} \mathrm{H}\right)$ is a significant industrialized chemical compound, which is known for its strong solubility in water and also used in cleaning surfaces, detergent \&rust remover, removing additional cement on tiling, efflorescence and other mineral deposits etc.

In this paper, an attempt made to report the growth and characterization of urea sulphamic nonlinear optical crystals by subjecting them to following characterization techniques namely XRD, FTIR, UV-Vis, TGA/DSC, Elastic Stiffness Constant and Second Harmonic Generation (SHG). The results of the mentioned characterization studies were reported and discussed.

\section{EXPERIMENTAL}

\section{Synthesis and Growth of Us Crystal}

The growth of Urea Sulphamic (US) NLO crystal was carried out by using conventional slow evaporation crystal growth technique. Urea: Sulphamic acids was taken in an equimolar ratio with double distilled water to obtain homogeneous mixture at room temperature. The chemical equation gives the relation for the synthesized crystals.

$$
\mathrm{H}_{2} \mathrm{NSO}_{3} \mathrm{H}+\mathrm{CH}_{4} \mathrm{~N}_{2} \mathrm{O} \rightarrow \mathrm{NH}_{2} \mathrm{SO}_{3}^{-} \mathrm{NH}^{3+} \mathrm{CONH}_{2}
$$

The chemicals used to grow the crystal was purified by repeated recrystallization, typically twice from double distilled water. Urea and Sulphamic acid were taken in 1:1 ratio and dissolved in distilled water. The prepared solution was stirred up to saturation state and filtered by using wattmen filter paper then transferred to a petri dish. The $100 \mathrm{ml}$ of a saturated and filtered solution of urea and sulphamic acid was kept in a dust-free place and maintained at room temperature.

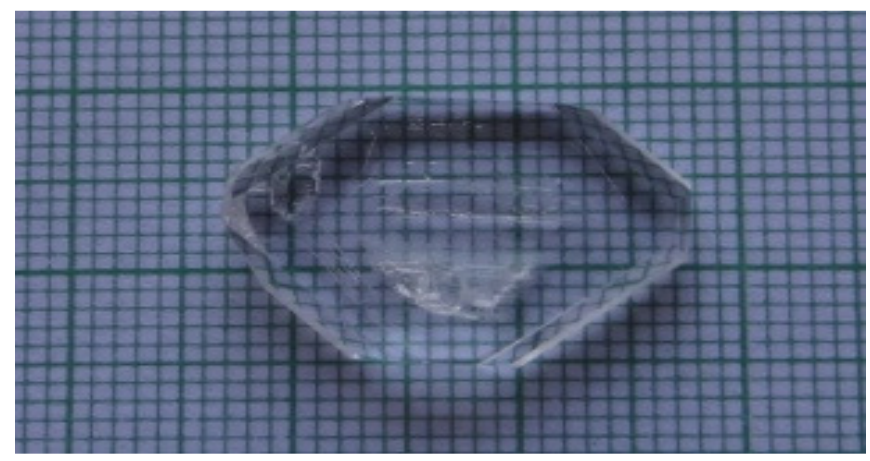

Fig.-1: The grown US Crystal

The crystals were grown by slow evaporation technique. In a period of 30 to 35 day's time, good quality optically transparent US crystal with a dimension of about $15 \times 15 \times 4 \mathrm{~mm}^{3}$ was harvested by spontaneous nucleation. The grown US crystal was shown in the Figure-1.

\section{Characterization}

The growth and characterization of US crystals were subjected to following characterization techniques XRD, FTIR, UV-Vis, TGA/DSC, Elastic Stiffness Constant and Second Harmonic Generation (SHG) for revealing the structure, vibrational modes, optical transmittance region, thermal nature and NLO property along with Hyperpolarizability calculations.

\section{Powder X-Ray Diffraction}

The grown crystals of US were subjected to crystal X-ray diffraction studies using Rigaku Ultima III XRay Diffractometer with a scintillation counter and monochromated $\mathrm{CuK \alpha} \alpha_{1}(\lambda=1.5406 \AA)$ radiation to 
RASĀYAN J. Chem.

Vol. 10 | No. 1 | 218 -225 | January - March | 2017

obtain the unit cell dimensions. The Powder X-Ray diffraction pattern is shown in Figure-2. Table-1 given the lattice parameters and crystal structure of grown US crystals. Sulphamic acid belongs to orthorhombic and urea crystals also belong to the orthorhombic structure. From Table-2, it is understood that the equimolar composition of urea and sulphamic and the number of planes and d-values are decreased. The decrease is attributed to the overlapping of planes of the sulphamic acid crystals and therefore there is a reorientation of the structure. This brings out different morphology of crystal in triclinic structure and space group of $\mathrm{P}_{-1}$. This observed phenomenon is very much striking and this mixed nature of urea and sulphamic acid NLO crystals will produce a wide range of laser active applications in the technological field.

Table-1: XRD Lattice Parameters of US Crystal

\begin{tabular}{c|c}
\hline Crystal System & $\begin{array}{c}\mathrm{P}_{-1} \\
\text { Triclinic }\end{array}$ \\
\hline $\mathrm{a}\left(\mathrm{A}^{0}\right)$ & 15.584 \\
\hline $\mathrm{b}\left(\mathrm{A}^{0}\right)$ & 10.796 \\
\hline $\mathrm{c}\left(\mathrm{A}^{0}\right)$ & 4.044 \\
\hline $\mathrm{V}\left(\AA^{3}\right)$ & 656.9 \\
\hline$\alpha(\theta)$ & 95.707 \\
\hline$\beta(\theta)$ & 96.137 \\
\hline$\gamma(\theta)$ & 76.949 \\
\hline
\end{tabular}

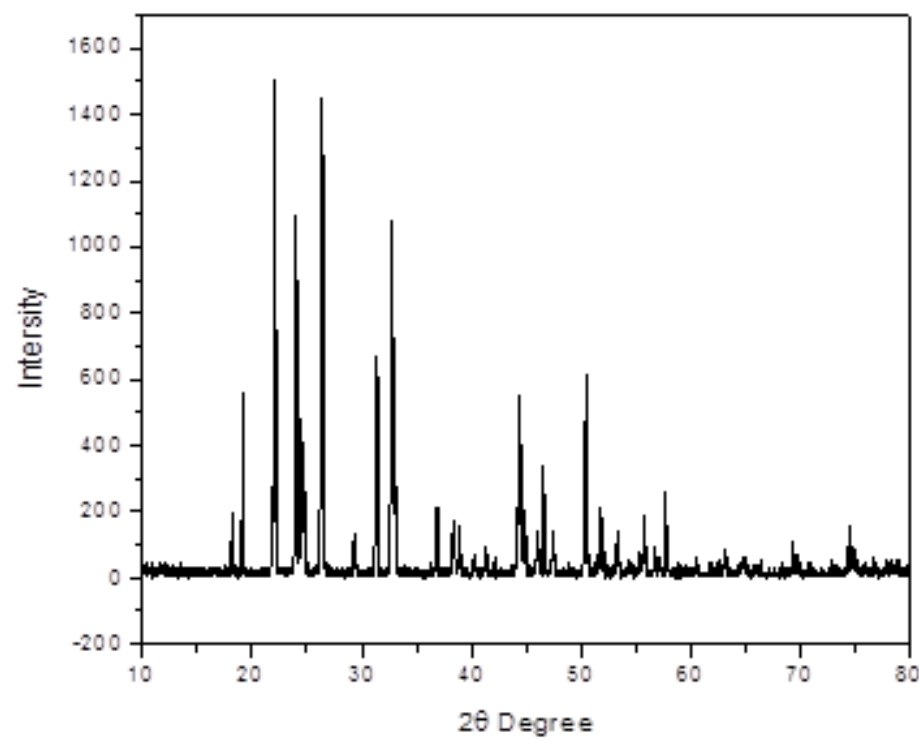

\section{FTIR Measurements}

Fig.-2: XRD Pattern of US Crystal

The grown crystals were subjected to FTIR analysis with a sample prepared with $\mathrm{KBr}$ in the palletized form. The FTIR spectrum for us was recorded in the region $4000-400 \mathrm{~cm}^{-1}$ employing Perkin Elmer make model spectrum Rx1Spectrometer. The FTIR spectrum of US is shown in Figure-3.

The broad envelope in the higher energy region 3948, 3154, 2875, 2557 and $2455 \mathrm{~cm}^{-1}$ is due to $\mathrm{NH}_{2}$ stretching vibrations. The prominent band 1266 and $1058 \mathrm{~cm}^{-1}$ may be assigned to a combination of the asymmetrical $\mathrm{C}-\mathrm{N}$ stretching vibration. In this envelope, the aromatic $\mathrm{C}-\mathrm{O}$ stretching vibrations at 1000 and $693 \mathrm{~cm}^{-1}$ are clearly evident. The absorption peaks characterizing the various functional groups are in very good agreement. The peaks at 2350 and $2021 \mathrm{~cm}^{-1}$ may be assigned to O-H stretching mode. The O-H bending vibrations are observed to produce intense bands at 1796 and $1559 \mathrm{~cm}^{-1}$. The bands at 
$1454 \mathrm{~cm}^{-1}$ which appear in $\mathrm{SO}_{3}{ }^{-}$deformation vibration. The weak bands at $538 \mathrm{~cm}^{-1}$ are assigned to N-S stretching. ${ }^{14,15}$

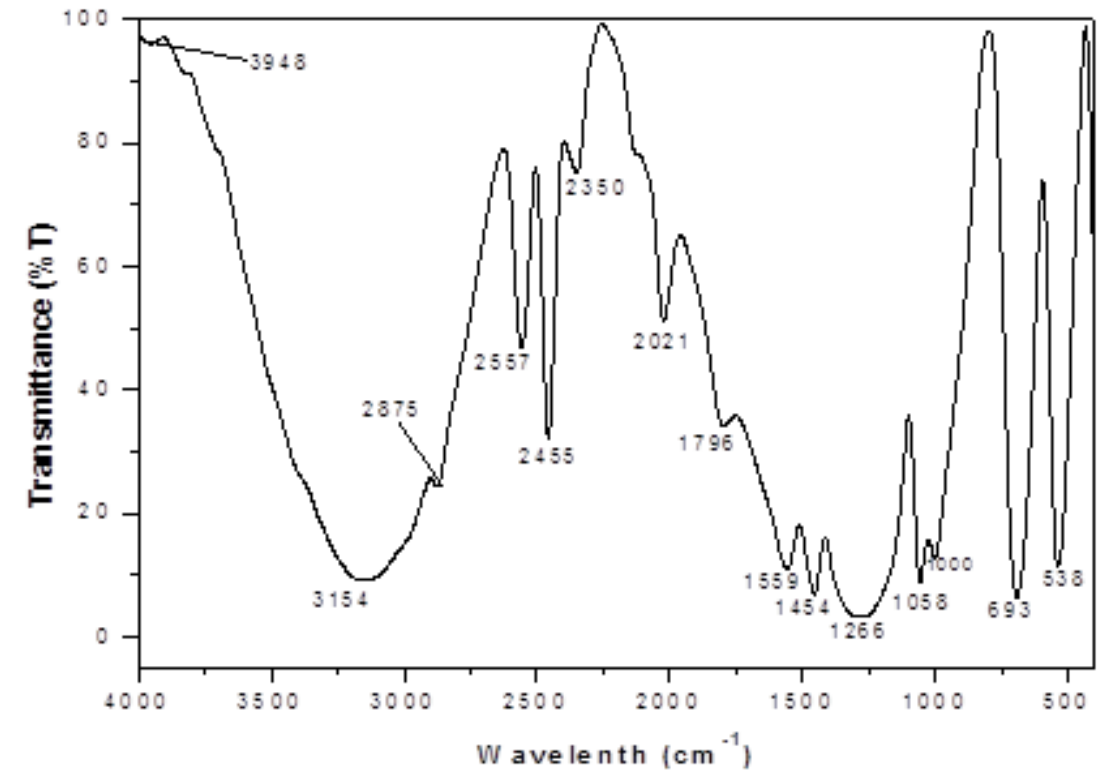

\section{UV-VIS Spectrum Analysis}

Fig.-3: FTIR Spectrum of US Crystal

The study of the optical transmission range of the grown crystals is thus very important because, US crystals are mainly used for optical applications. The UV-Visible transmission spectra were recorded using Perkin Elmer make model Lambada 35 UV-Vis-NIR Spectrophotometer to know the stability for optical application in the range $200 \mathrm{~nm}$ to $1100 \mathrm{~nm}$. From the spectra in the Figure-4. It was observed that the US crystals showed good transmittance in the entire visible regions. The UV cut-off wavelength of US crystal is found to be at $236 \mathrm{~nm}$ and there is no considerable transmission till $1100 \mathrm{~nm}$. The overlay UV-Vis spectra clearly show that the optical quality of US crystals. The US crystals have minimum absorption in the entire region between $250-1100 \mathrm{~nm}^{16,17}$ The results are good agreement with the reported value.

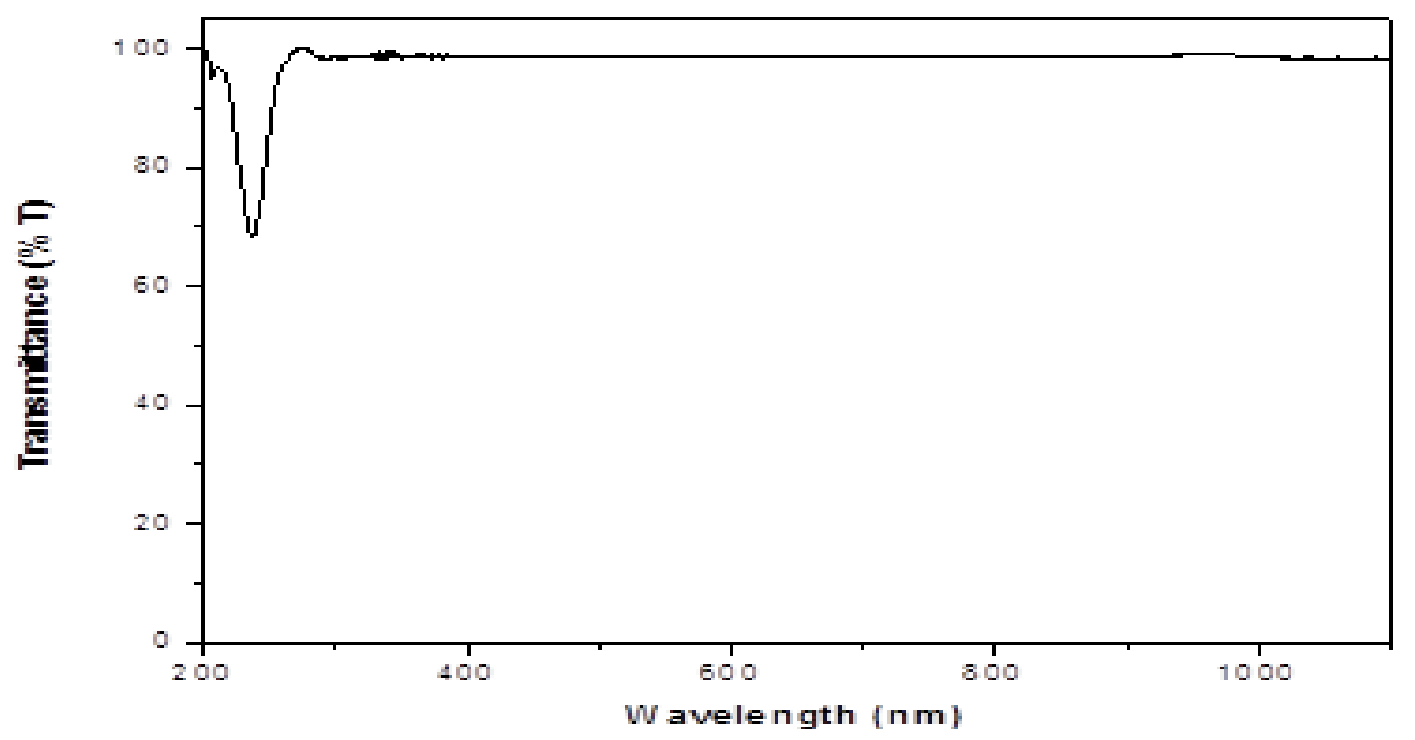

Fig.-4: UV -Vis Spectrum of US Crystal 


\section{Elastic Stiffness Constant}

The elastic stiffness constant $\left(\mathrm{C}_{11}\right)$ was calculated for different loads using Wooster's empirical formula $\mathrm{C}_{11}=\mathrm{H}_{\mathrm{v}}^{7 / 4}$. The $\mathrm{C}_{11}$ values are shown in Table-2. These values give an idea about the tightness of bonding between neighboring atoms. The high value shows that the binding forces between the atoms were quite strong. It was calculated for the loads from $25 \mathrm{gm}$ to $100 \mathrm{gm}$. The Plot of Hv versus Elastic Stiffness Constant for the title crystal is shown in Figure-5.

Table-2: Elastic Stiffness Constant of US Crystal

\begin{tabular}{c|c}
\hline Load $(\mathrm{g})$ & $\mathrm{C}_{11}\left(10^{14} \mathrm{~Pa}\right)$ \\
\hline 25 & 33.30997635 \\
\hline 50 & 35.18250329 \\
\hline 100 & 43.62457472 \\
\hline
\end{tabular}

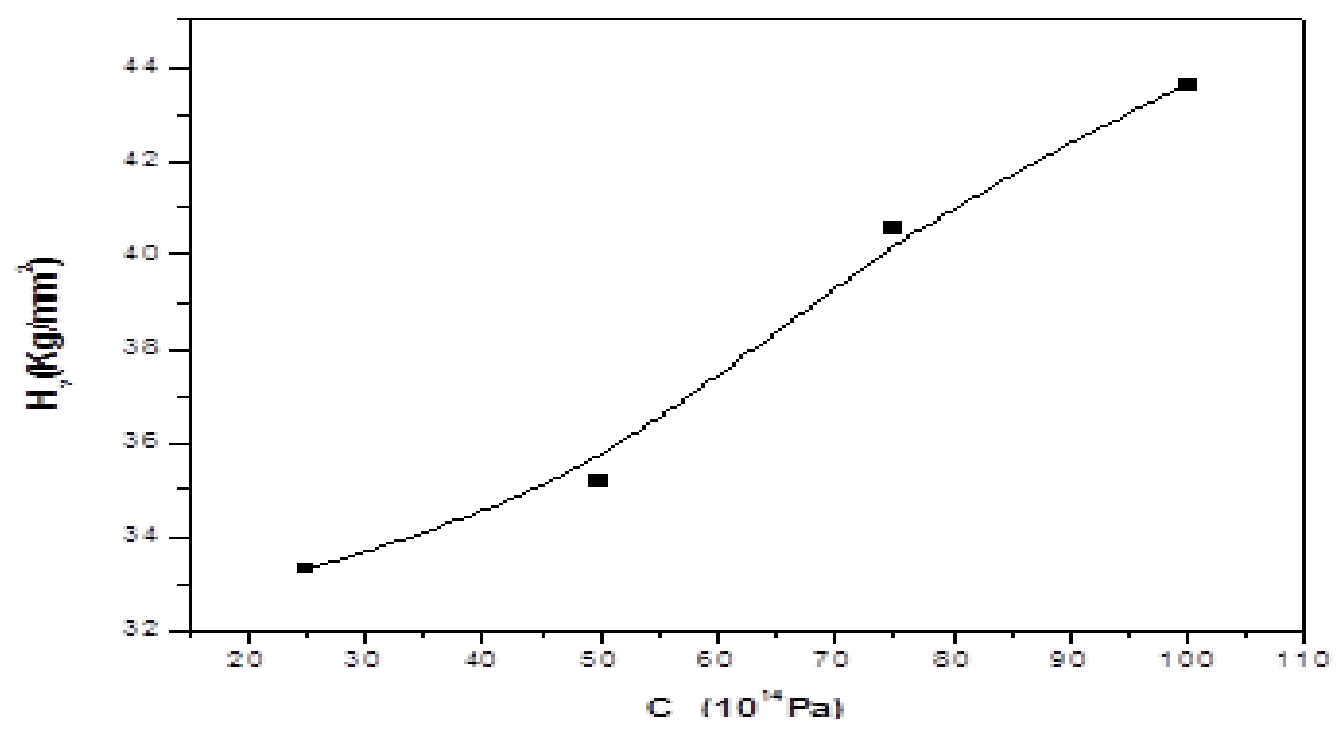

Fig.-5: Plot of $\mathrm{H}_{\mathrm{v}}$ V/s Load of Elastic Stiffness Constant

\section{TGA and DSC Thermal Analysis}

Thermal characterization technique was used to find the optimum formation temperature for the compound. The thermo gravimetric analysis of US was carried out in the temperature range of $100-800^{\circ} \mathrm{C}$ in air at a heating rate of $20^{\circ} \mathrm{C} / \mathrm{min}$. The TGA analysis is shown in Figure-6.

There is no water in the crystal lattice as there is no weight loss between $100^{\circ} \mathrm{C}$ and $200^{\circ} \mathrm{C}$. The first exothermic process occurring near $250^{\circ} \mathrm{C}$ may be associated with the departure of water molecules during thermal decomposition of the precursor. In the range between 350 and $800^{\circ} \mathrm{C}$, a large exothermic peak appeared at $490^{\circ} \mathrm{C}$ in TGA graph due to the thermal effect for precursor decomposition and the maximum loss occurred at this stage. Differential scanning calorimetric (DSC) measurement was carried out with ground crystals of US. The DSC curve showed in figure- 6 clearly indicates that there is no phase transition up to $200^{\circ} \mathrm{C}$. DSC curve exhibits one endothermic peak on the heating curves at $245^{\circ} \mathrm{C}$. The sharpness of the peaks shows a good degree of crystalline of the sample. The DSC studies of US crystal confirms that it was stable up to its melting point.

\section{NLOSHG Study and Hyperpolarizability Calculations}

The NLO materials have many practical applications in research and industries. ${ }^{18}$ The SHG property in urea doped SA powdered sample was studied using Q-switched ND: YAG laser by employing Kurtz powder technique ${ }^{18}$. The SHG measurement was carried out using Q-switched mode-locked with 
wavelength at $1064 \mathrm{~nm}$, with the input beam energy of $2.5 \mathrm{~mJ} / \mathrm{p}$ and a pulse width of $10 \mathrm{~ns}$ at a repetition rate of $10 \mathrm{~Hz}$. The standard KDP crystal gave an SHG of $10 \mathrm{mV} /$ pulse. Pulse energy and pulse width are maintained as $300 \mathrm{~mJ} \mathrm{~s}^{-1}$ and $10 \mathrm{~ns}$ respectively. The second harmonic signal was about $50 \mathrm{mV}$ which was greater than that of KDP crystal as a reference material from the same input energy. There was green light emission was observed for US. Hence it was confirmed that the grown specimen have NLO efficiency of US was 1.1 times greater than that of KDP.

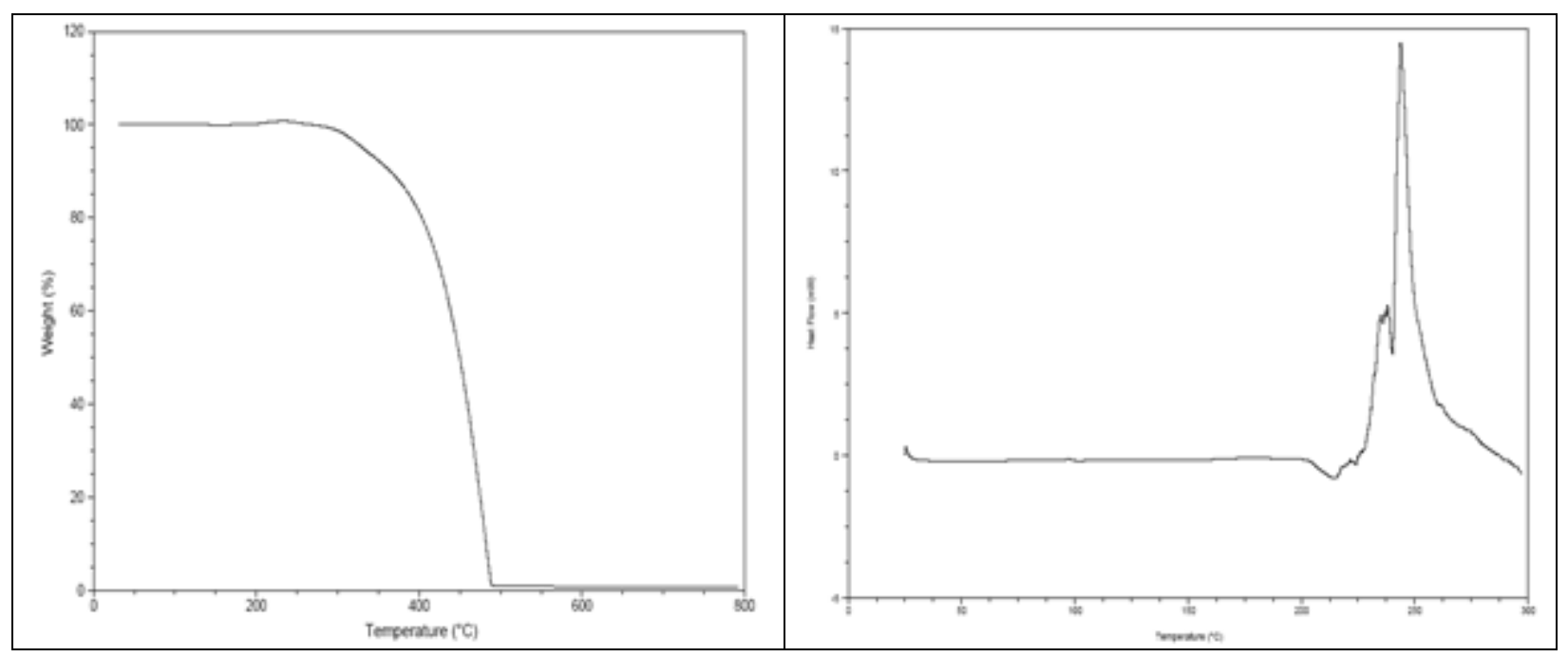

Fig.-6: TGA - DSC Curves for US Crystal

For the first time, we have tried to prove the NLO efficiency of the US by the calculative method using Hyperpolarizability. The first hyperpolarizability $(\beta 0)$ of this novel molecular system and related properties $\left(\beta 0, \alpha_{0}\right.$ and $\left.\Delta \alpha\right)$ of are calculated using B3LYP/6-311+G (d, p) basis set, based on the finitefield approach. In the presence of an applied electric field, the energy of a system is a function of the electric field. First, hyperpolarizability is a third rank tensor that can be described by a $3 \times 3 \times 3$ matrix. 27 Components of the 3D matrix can be reduced to 10 components due to the Kleinman symmetry ${ }^{19}$. It can be given in the lower tetrahedral format. It is obvious that the lower part of the $3 \times 3 \times 3$ matrixes is tetrahedral. The components of $\beta$ are defined as the coefficients in the Taylor series expansion of the energy in the external electric field. When the external electric field is weak and homogeneous, the expansion becomes:

$$
E=E^{0}-\mu_{\alpha} F-1 / 2 \alpha_{\alpha \beta} F_{\alpha} F_{\beta}-1 / 6 \beta_{\alpha \beta \gamma} F_{\alpha} F_{\beta} F_{\gamma}+\ldots
$$

Where, $\mathrm{E}^{0}$ is the energy of the unperturbed molecules, $\mathrm{F} \alpha$ the field at the origin, $\mu \alpha_{\iota} \alpha \alpha \beta \beta \alpha \beta \gamma$ are the components of dipole moment, polarizability, and the first hyperpolarizabilities respectively. The total static dipole moment $\mu$, the mean polarizability $\alpha 0$, the anisotropy of the polarizability $\Delta \alpha_{\iota}$ and the mean first hyperpolarizability $\beta 0$, using the $\mathrm{x}, \mathrm{y}, \mathrm{z}$ components they are defined as:

$$
\begin{aligned}
& \mu=\left(\mu_{\mathrm{x}}^{2}+\mu_{\mathrm{y}}^{2}+\mu_{\mathrm{z}}^{2}\right)^{1 / 2} \\
& \alpha_{0}=\frac{\alpha_{\mathrm{xxx}}+\alpha_{\mathrm{yy}}+\alpha_{\mathrm{zz}}}{3} \\
& \alpha=2^{-1 / 2}\left[\left(\alpha_{x x}-\alpha_{y y}\right)^{2}+\left(\alpha_{y y}-\alpha_{z z}\right)^{2}+\left(\alpha_{z z}-\alpha_{x x}\right)^{2}+6 \alpha^{2} x x\right]^{1 / 2} \\
& \beta_{0}=\left(\beta_{x}^{2}+\beta_{y}^{2}+\beta_{z}^{2}\right)^{1 / 2}
\end{aligned}
$$

and 
$\beta_{x}=\beta_{x}+\beta_{x y y}+\beta_{x z z}$

$\beta_{y}=\beta_{y y y}+\beta_{x y y}+\beta_{x z z}$

$\beta_{x}=\beta_{x}+\beta_{x y y}+\beta_{x z z}$

Dipole moment $(\mu)$ in Debye, hyperpolarizability $\beta(-2 \omega ; \omega, \omega) 10^{-30}$ esu. The calculated first-order hyperpolarizability ( $\beta$ total) of Urea Sulphamic acid is $1.023 \times 10^{-30} \mathrm{esu}$, which is nearly 1.1 times greater than that of urea $\left(0.1947 \times 10^{-30} \mathrm{esu}\right)$. The calculated dipole moment $(\mu)$ and first-order hyperpolarizability $(\beta)$ are shown above. The results were tabulated in Table-3. The hyperpolarizability results are very good with the NLOSHG test results and UV- Visible Spectrum. The US crystals are a potential candidate for the NLO applications.

Table-3: The Dipole Moment $(\mu)$ and First Order

Hyperpolarizability ( $\beta$ ) of Urea Sulphamic Acid Crystal Derived from DFT Calculations

\begin{tabular}{c|c}
\hline$\beta \xi \xi \xi$ & -56.733 \\
\hline$\beta \psi \xi \xi$ & -16.503 \\
\hline$\beta \psi \psi \xi$ & -18.506 \\
\hline$\beta \psi \psi \psi$ & -25.772 \\
\hline$\beta \xi \xi \zeta$ & -24.042 \\
\hline$\beta \zeta \psi \xi$ & 9597.3 \\
\hline$\beta \psi \psi \zeta$ & -283.68 \\
\hline$\beta \zeta \zeta \xi$ & -15.878 \\
\hline$\beta \zeta \zeta \psi$ & 9436.8 \\
\hline$\beta \zeta \zeta \zeta$ & 48.186 \\
\hline$\beta \lambda \alpha \tau \sigma \tau$ & 1.023 \\
\hline$\mu \mathrm{x}$ & 1.4920256 \\
\hline$\mu \mathrm{y}$ & 0.2263247 \\
\hline$\mu \mathrm{z}$ & 0.1124329 \\
\hline$\mu$ & 1.3530644 \\
\hline
\end{tabular}

\section{CONCLUSION}

Good optical quality single crystal of US has been grown by slow evaporation techniques from aqueous solution. Powder XRD studies confirm the crystalline nature of the crystal as triclinic structure. The FTIR studies reveal the functional groups of grown crystal. The optical transparency has been assessed by UVVis spectroscopy and the cut-off wavelength was found to be around $236 \mathrm{~nm}$. The elastic stiffness constant graph shows that tightness of bonding between neighboring atoms. The thermal studies of US crystal indicate the high stability of the grown crystal. The SHG efficiency of US was measured using Kurtz and Perry method and is found to be about 1.1 times that of the standard KDP crystal. The NLO results are compared with hyperpolarizability calculations.

\section{REFERENCES}

1. K. Ambujam, C.Preema Thomas, S. Aruna, D. Prem Anand, P. Sagayaraj, Mat. \& Manufact. Processes, 22, 346 (2007)

2. D. Ledoux, A. Lepers, J. Perigaud, J. Badan, and J. Zyss, Opt. Commun., 80, 149 (1990)

3. A. Jegatheesan, B. Ravi, B. Neelagandaprasad and G. Rajarajan, Rasayan Journal of Chemistry, 7,353 (2014)

4. K. Sankaranarayanan and P. Ramasamy, J. Cryst. Growth, 193, 252 (1998)

5. J. R. Dyer, Applications of Absorption Spectroscopy of Organic Compounds, Prentice Hall of India Private Ltd., New Delhi, 2005

UREA SULPHAMIC ACID CRYSTAL 
RASĀYAN J. Chem.

Vol. 10 | No. 1 |218 -225 | January - March | 2017

6. N. Senthilvelan, G. Rajarajan and S. Sivakumar, International Journal of ChemTechResearch,6, $5692(2014)$

7. T. Jayanalina and G. Rajarajan, International Journal of Computer Applications,49,33(2012)

8. F.A. Kanda and A.J.King, J. Am. Chem. Soc.,73, 2315 (1951)

9. K. Cheng, W.R. Bosenberg and C.L. Tang, Prog. Cryst. Growth Charact.,20, 9 (1990)

10. W.R. Donaldson and C.L. Tang, Appl. Phys. Lett.,44, 25 (1984)

11. G.C. Catella, J.H. Bohn and J.R. Luken, IEEE J. Quantum Electron.,24, 1201 (1988)

12. T. Rajalakshmi, R. Dhanasekaran and P. Ramasamy, J. Mater. Sci. Lett.,12, 1797 (1993)

13. S. Kalaiselvan and G. Pasupathi, Der Pharma Chemica,4,5 (2012)

14. B. Kannan, P. R.Seshadri , Indian Journal of Science and Technology, 6,4908 (2013)

15. B.N. Moolya, A. Jayarama, M.R. Sureshkumar and S.M. Dharmaprakash, J.Cryst. Growth, 280, 581 (2005)

16. S. Rajyalakshmi, B. Brahmaji, K. Samatha, K. Ramachandra Rao, M.C. Rao, Journal of Optoelectronics and Biomedical Materials, 7,4(2015)

17. R.K. Khanna and P.J. Miller, Spectrochim. Acta,26A, 1667 (1970)

18. S.K. Kurtz and T.T. Perry, J. Appl. Phys.,39, 3798 (1968)

19. D. A. Kleinman, Phys.Rev., 126, 1977 (1962)

[RJC-1565/2017] 